\title{
The Influence of Leadership Styles on the Implementation of the Strategic Plans in Non-Governmental Organisations in Kisumu County, Kenya
}

\author{
Ogal Joram", Omanyo Abraham Otieno ${ }^{2}$ \\ ${ }^{1}$ Department of Business, Jaramogi Oginga Odinga University of Science and Technology, Bondo, Kenya \\ ${ }^{2}$ Department of Psychology, Maseno University, Kisumu, Kenya
}

Email address:

joramogal@gmail.com (O. Joram), abrahamotieno@yahoo.com (O. Joram)

\section{To cite this article:}

Ogal Joram, Omanyo Abraham Otieno. The Influence of Leadership Styles on the Implementation of the Strategic Plans in NonGovernmental Organisations in Kisumu County, Kenya. European Business \& Management. Vol. 4, No. 1, 2018, pp. 18-23. doi: 10.11648/j.ebm.20180401.13

Received: September 29, 2017; Accepted: October 27, 2017; Published: December 23, 2017

\begin{abstract}
Despite the evidence of the existence of strategic plans in nongovernmental organizations in Kenya, the greatest impediment to successful use of these strategies in development has been failure by organizations to implement them. Indeed, previous studies have shown that crafting strategic plans is a lot easier than to make them happen. The objective of the study was to find out the influence of leadership styles on the implementation of the strategic plans. The sample size of this descriptive survey design study was 10 Human Resource Managers and 70 financial officers giving a total of 80 respondents which has been selected through saturated sampling techniques. The study used questionnaires and interview schedules to collect data. The validity of the research instrument was ensured by conducting a pre-test study in three NGOs from the neighboring county. Data collected was analyzed using measures of central tendency, mean and median. The quantitative data was analyzed through descriptive statistics while qualitative findings were thematically analyzed. Results indicated that majority of the leaders (90.48\%) in NGOs in Kisumu County do not have skills and abilities required to ensure effectiveness in the implementation of the strategic plans. There was high positive correlation $(\mathrm{r}=.854)$ between leadership styles and the implementation of the strategic plans. The study recommended that Non-Governmental Coordination Board (NGCB) should advice NGOs on a leadership style that will provide direction, implementing plans and motivating NGOs in Kisumu County towards implementing strategic plans.
\end{abstract}

Keywords: Leadership Styles, Strategic Plan, And Strategic Plan Implementation

\section{Introduction}

Strategy implementation is a term used to describe the activities within an organization to manage the execution of a strategic plan. According to Allison \& Kaye [1], a strategic plan is a document used to communicate with the organization of the organizations goals, the actions necessary to achieve those goals and all of the other critical elements developed during the planning exercise.

In New York, Kanter, Stein \& Jick [6] carried out a study to explore leaders' effectiveness in implementing organizational change and the processes, skills, abilities required for such effectiveness. Leaders in complex organizations are now responsible for creating and nurturing conditions which will enable fast, innovative adaptations to change. Indeed, leaders and managers are responsible for change strategy, implementation, and monitoring, thus they function as change agents (Kanter, Stein \& Jick, [6]). However, they must take into consideration that there is a part of unknown, which they will never control. As a result, the challenge of managing change is one of the most essential and enduring roles of leaders while current rapid organizational changes has made effective leadership more imperative. Resistance to change is a dead-end street. In today's business world, organizations that support and implement continuous and transformational change remain competitive. Many researchers have attempted to explain why change is so difficult to achieve, and develop models to 
manage the change process. Despite the numerous theories, models, and multi-step approaches, leaders continue to lack a clear understanding on the implementation of strategic plans, its antecedents, effective processes or the ability to successfully implement organizational change and how to engage members in change initiatives, therefore this leaves a gap that was fulfilled by the proposed study.

Loveren, [8] from University of South Floridaexamined how employees' perceptions of leadership, decision-making, and relationships are associated with their perception of a development operations' effectiveness. Deans, development officers, central development staff, and unit development staff at the University of South Florida were surveyed via email. The results indicated that employees' perceptions of leadership, decision-making, and relationships are strongly related to their perceived job satisfaction, trust, commitment, and control mutuality and consequently their perception of the development operation's effectiveness. The reviewed study surveyed respondents via email while the proposed study surveyed the respondents through face to face discussion using written questions. Furthermore, the reviewed study examined how employees' perceptions of leadership, decision-making, and relationships are associated with their perception of a development operations' effectiveness while the proposed study established how leadership styles influences implementation of strategic plans in the NGOs within Kisumu region thus filling the gap.

In Nigeria, Ballantyne, [4] carried a study whose purpose was to help leaders recognize the importance of utilizing a strategic focus to enhance achievement in a highly competitive global environment. According to his findings, leadership theories allow most managers to be classified into a specific leadership framework. This framework can provide clues as to how leaders make decisions. In the competitive environment in which organizations operate today, leaders need to evaluate the assumptions utilized in decision-making. In our society where information and knowledge are expanding exponentially, a new model may assist leaders which incorporate the stakeholders into the decision-making process. Whether a leader is classified as a charismatic, a shared, a distributive, a collaborative or an authoritative leader, a new focus may be necessary in order to be successful in the new global environment. The proposed study was set to find out how these leadership styles influences the implementation of strategic plans for the attainment of vision 2030 among NGOs in Kisumu County.

Reilly, Caldwel and Self, [13] in South Africa carried out a descriptive study on how leadership matters: The effects of leaders' alignment on strategy implementation. They established that leaders behavior influences group and organizational behavior, but we know less about how senior leaders ensure that strategic plans is implemented as well as ensuring that group and organizational members implement their decisions. Furthermore, they found that it was only when leaders' effectiveness at different levels was considered in the aggregate that significant performance improvement occurred. Therefore, most of the NGOs have multiple layers of leaders, implying that any single leader does not lead in isolation. Hence, this study focused on how the consistency of leadership effectiveness across hierarchical levels influenced the implementation of a strategic initiative in realization to vision 2030 .

In Nairobi, Chege, [5] sought to analyze the effect of leadership styles on implementation of strategic plans in Small and Medium Enterprises (SMEs). Specifically the study: analyzed the effect of autocratic leadership style, assessed the effect of democratic leadership style and evaluated the effect of laissez faire leadership style on implementation of strategic plans in SMEs. Descriptive research design was used. A sample of 354 SMEs was selected using stratified random sampling. The regression showed that autocratic leadership had the highest effect of implementation of strategic plans with a coefficient of 0.488 , followed by democratic leadership with a coefficient of 0.384 and laissez faire with a coefficient 0.269 . The reviewed study was on the effect of leadership styles on implementation of strategic plans in Small and Medium Enterprises (SMEs) whereas the proposed study focused on the effects of leadership styles on the implementation of strategic plans within Kisumu region. Hence, the proposed study established how organizations use all the three leadership styles to maximize implementation of strategic plans.

Koech and Namusunge [7] conducted a study on the effect of leadership styles on organization performance. The study was in States Corporation at Mombasa, Kenya. One of the key variables was laissez faire leadership, transactional and transformational leadership style. The result of the study showed that laissez faire leadership is not significantly correlated to organizational performance. Based on the findings the study recommended that manager should discard laissez faire leadership by becoming more involved in guiding their subordinates, managers should formulate and implement effective reward and recognition system during strategic plans implementation. The reviewed study was on the effect of leadership styles on organization performance but not on the strategic plans implementation for the attainment of vision 2030 among NGOs within Kisumu region hence, filling the gap.

\subsection{Statement of the Problem}

Despite the evidence of the existence of strategic plans in nongovernmental organizations in Kenya, the greatest impediment to successful use of these strategies in development has been failure by organizations to implement them. Indeed, previous studies have shown that crafting strategic plans is a lot easier than to make them happen. The objective of the study was to find out the influence of leadership styles on the implementation of the strategic plans.

\subsection{Hypotheses}

$\mathrm{H}_{\mathrm{O}}$ : There is no statistically significant relationship between leadership style and the implementation of strategic plan in NGOs in Kisumu County. 
$\mathrm{H}_{\mathrm{A}}$ : There is statistically significant relationship between leadership style and the implementation of strategic plan in NGOs in Kisumu County.

\section{Methods}

The sample size (as shown in Table 1) of this descriptive survey design study was 10 Human Resource Managers and 70 financial officers giving a total of 80 respondents which has been selected through saturated sampling techniques. The study used questionnaires and interview schedules to collect data. The validity of the research instrument was ensured by conducting a pre-test study in three NGOs from the neighboring county. Data collected was analyzed using measures of central tendency, mean and median. The quantitative data was analyzed through descriptive statistics while qualitative findings were thematically analyzed.

Table 1. Sample Size Determination.

\begin{tabular}{lll}
\hline Respondent & Population & Sample Size (n) \\
\hline Human Resource Managers & 70 & 10 \\
Financial Officers & 70 & 70 \\
Total & 140 & 80 \\
\hline
\end{tabular}

Source: Researcher's Data

\section{Results and Discussions}

\subsection{Questionnaires Return Rate}

The study achieved $90 \%$ response return rate of the finance officers in which out of the 70 respondents that were expected in the study, 63 finance officers, duly filled the questionnaires, implying that all except 7 respondents who participated in the study did not fill questionnaires appropriately. As for the Human Resource Managers, all the 10 chief executive officers took part in the interview attaining $100 \%$ response return rate. These response return rate was achieved because the researcher administered the instruments to each respondent and also organized the interviews with the HRMs in person to ensure that each and every respondent took part in the study.

\subsection{Respondents Demographic Characteristics}

The data used in this study was drawn from the population of 63 finance officers from 63 NGOs in Kisumu County. The sampled finance officers respondents were 70 finance officers $(\mathrm{N}=70)$. Hence from the NGOs there were $(n=63) 63$ finance officers' respondents. Demographic characteristics of the finance officers who participated in the study were varied as summarized in Table 2. Age of the finance officers was sought because it plays a role when it comes to the experience among finance officers since aged finance officers in NGOs are having vast knowledge in the implementation of strategic plans by the Non-governmental organizations in Kisumu County. Moreover, age of the respondents increased the credibility of the data collected because the age brings in the maturity and understanding of the subject on the area of study. Table 2 shows the percentage distribution of the finance officer respondents in terms of their demographic characteristics.

Table 2. Summary of Demographic characteristics of respondents $(n=63)$ in Kisumu County.

\begin{tabular}{llll}
\hline Respondent Category & $\begin{array}{l}\text { Female, } \mathbf{n} \\
(\mathbf{\%})\end{array}$ & $\begin{array}{l}\text { Male, } \mathbf{n} \\
(\%)\end{array}$ & $\begin{array}{l}\text { Total n, } \\
(\mathbf{\%})\end{array}$ \\
\hline $\begin{array}{l}\text { Finance Officers' Gender } \\
\text { HRMs }\end{array}$ & $\begin{array}{l}28(44.44) \\
4(40.0)\end{array}$ & $\begin{array}{l}35(55.56) \\
6(60.0)\end{array}$ & $\begin{array}{l}63(100.0) \\
10(100.0)\end{array}$ \\
Age of the Finance Officers (FO) & & & \\
Below 25 years. & $5(7.94)$ & $4(92.06)$ & $9(14.29)$ \\
25-35 years. & $12(19.05)$ & $19(80.95)$ & $31(49.21)$ \\
45-54 years. & $10(15.87)$ & $8(84.13)$ & $18(28.57)$ \\
Over 54 years. & $1(1.59)$ & $4(98.41)$ & $5(7.94)$ \\
Level of Qualifications of the FO & & & \\
Certificate. & - & - & - \\
Diploma & $6(9.52)$ & $11(90.48)$ & $17(26.98)$ \\
Degree & $13(20.63)$ & $14(79.37)$ & $27(42.86)$ \\
Masters & $9(14.29)$ & $8(85.71)$ & $17(26.98)$ \\
PhD. & - & $2(3.17)$ & $2(3.18)$ \\
Work experience & & & \\
1-5 years. & $13(20.64)$ & $17(79.36)$ & $20(31.75)$ \\
5-10 years. & $12(19.05)$ & $20(80.95)$ & $32(50.79)$ \\
10+ years. & $3(4.76)$ & $8(95.24)$ & $11(17.46)$ \\
\hline
\end{tabular}

Source: Researcher's data 2016; Values in parentheses indicate \% of total (n $=63$ ). B Indicates row percentage.

Considering the response by gender, majority of the finance officers were males at $35(55.56 \%)$ while their female counterparts were represented by 28 (44.44\%). This implies that the number of male finance officers outnumbered their female counterparts. The study also established that $6(60.0 \%)$ of the chief executive officers were males while, only $4(40.0 \%)$ were females. The leadership gap between the male and female could be explained by the fact that several factors influence female finance officers in accessing leadership positions than their male counterparts.

Moreover, majority of the finance officers 31 (49.21\%) were aged between 25-35 years followed by 18 (28.57\%) of the respondents who were aged of 45-54 years each. $9(14.29 \%)$ of them were aged below 25 years while the rest $5(7.94 \%)$ of the finance officers' respondents were over 54 years of age. The findings indicate that there were more males than females in the age groups; 25-35 years and over 54 years whereas there were more females than males in the age groups; 25-35 years and below 25 years. On average, female finance officers are younger compared to male finance officers?

The study established that most of the respondents (finance officers) at $27(42.86 \%)$ were degree holders, followed by those with diploma and masters holders at 17 (26.98\%) each, those with $\mathrm{PhD}$ holders were accounted for by $2(3.18 \%)$ and they were only males. This shows that majority of the respondents had good education background on the implementation of strategic plans by the Non-governmental organizations in Kisumu County hence were more reliable in giving the information.

The study found that majority of the respondents (finance officers) at $32(50.79 \%)$ cumulatively had taken 5-10 years offering their services as finance officers in Non- 
governmental organizations settings. Furthermore, 20 $(31.75 \%)$ of the finance officers had work experience of $1-5$ years whereas $11(17.46 \%)$ of the finance officers had taken $10+$ years offering services as finance officers. This implies that they had good experience and were therefore able to give information on the factors affecting the implementation of strategic plans by the Non-governmental organizations in Kisumu County.

\subsection{Influence of Leadership Styles on the Implementation of the Strategic Plans}

In the first research objective, the study sought to find out influence of leadership styles on the implementation of the strategic plans in NGOs in Kisumu County. This was crucial because it would help in establishing the factors affecting the implementation of strategic plans by the Non-governmental organizations in Kisumu County. Respondents (finance officers) were therefore asked to indicate their level of agreement with the following statement based on; SA Strongly Agree; A Agree; D Disagree; U Undecided SD strongly disagree, while for the sake of mean interpretation, 5=SA Strongly; 4=A Agree; 3= D Disagree; 2=U Undecided $1=\mathrm{SD}$. Table 3 shows the response.

Table 3. Influence of leadership styles on the implementation of the strategic plans.

\begin{tabular}{|c|c|c|c|c|c|c|c|}
\hline Statement & & SA & $\mathbf{A}$ & $\mathbf{U}$ & D & SD & Mean \\
\hline \multirow{2}{*}{$\begin{array}{l}\text { My leaders have skills and abilities required to ensure effectiveness in the } \\
\text { implementation of the strategic plans }\end{array}$} & $\mathrm{F}$ & 4 & 2 & 0 & 27 & 30 & \multirow{2}{*}{2.185} \\
\hline & $\%$ & $6.35 \%$ & $3.17 \%$ & - & $42.86 \%$ & $47.62 \%$ & \\
\hline \multirow{2}{*}{$\begin{array}{l}\text { My leaders creates and nurtures conditions which will enable fast } \\
\text { implementation of the strategic plans }\end{array}$} & $\mathrm{F}$ & 11 & 9 & 3 & 22 & 18 & \multirow{2}{*}{3.204} \\
\hline & $\%$ & $17.46 \%$ & $14.29 \%$ & $4.76 \%$ & $34.92 \%$ & $28.57 \%$ & \\
\hline \multirow{2}{*}{$\begin{array}{l}\text { My leaders has ensured transformational change in the Organization that has } \\
\text { enhances implementation of the strategic plans }\end{array}$} & $\mathrm{F}$ & 10 & 9 & 2 & 19 & 23 & \multirow{2}{*}{3.852} \\
\hline & $\%$ & $15.87 \%$ & $14.29 \%$ & $3.17 \%$ & $30.16 \%$ & $36.51 \%$ & \\
\hline $\begin{array}{l}\text { My leaders have clear understanding on the implementation of strategic plans } \\
\text { or the ability to successfully implement organizational change }\end{array}$ & $\mathrm{F}$ & 21 & 13 & 3 & 16 & 10 & 3.926 \\
\hline \multirow{2}{*}{$\begin{array}{l}\text { My perceptions of leadership and decision-making affects my commitments } \\
\text { into the implementation of the strategic plans }\end{array}$} & $\mathrm{F}$ & 31 & 20 & 1 & 6 & 5 & \multirow{2}{*}{4.648} \\
\hline & $\%$ & $49.21 \%$ & $31.75 \%$ & $1.59 \%$ & $9.52 \%$ & $7.94 \%$ & \\
\hline \multirow{2}{*}{$\begin{array}{l}\text { I agree to the fact that whether a leader is classified as a charismatic, a shared, } \\
\text { a distributive, a collaborative or an authoritative leader, a new focus may be } \\
\text { necessary in order to successfully implement strategic plans }\end{array}$} & $\mathrm{F}$ & 36 & 24 & 0 & 3 & 0 & \multirow{2}{*}{4.759} \\
\hline & $\%$ & $57.14 \%$ & $38.1 \%$ & $0.0 \%$ & $4.76 \%$ & $0.0 \%$ & \\
\hline \multirow{2}{*}{ I agree that leaders behavior influences group and organizational behavior } & $\mathrm{F}$ & 29 & 19 & 2 & 6 & 7 & \multirow{2}{*}{4.574} \\
\hline & $\%$ & $46.03 \%$ & $30.16 \%$ & $3.17 \%$ & $9.52 \%$ & $11.11 \%$ & \\
\hline Autocratic leadership style influences implementation of the strategic plans & $\%$ & $63.49 \%$ & $12.70 \%$ & $4.76 \%$ & $15.87 \%$ & $3.17 \%$ & 4.537 \\
\hline \multirow{2}{*}{ Democratic leadership style influences implementation of the strategic plans } & $\mathrm{F}$ & 38 & 15 & 0 & 10 & 0 & \multirow{2}{*}{2.111} \\
\hline & $\%$ & $60.32 \%$ & $23.81 \%$ & $0.0 \%$ & $15.87 \%$ & $0.0 \%$ & \\
\hline \multirow{2}{*}{ Laissez faire leadership influences implementation of the strategic plans } & $\mathrm{F}$ & 20 & 34 & 1 & 6 & 2 & \multirow{2}{*}{2.111} \\
\hline & $\%$ & $31.75 \%$ & $53.97 \%$ & $1.59 \%$ & $9.52 \%$ & $3.17 \%$ & \\
\hline \multirow{2}{*}{$\begin{array}{l}\text { Transactional and transformational leadership style influences implementation } \\
\text { of the strategic plans }\end{array}$} & $\mathrm{F}$ & 36 & 10 & 2 & 8 & 7 & \multirow{2}{*}{4.426} \\
\hline & $\%$ & $57.14 \%$ & $15.87 \%$ & $3.17 \%$ & $12.70 \%$ & $11.11 \%$ & \\
\hline
\end{tabular}

Source: Researcher's Data (2016)

According to the findings in table 3 ; the results indicated that majority of the leaders $(90.48 \%)$ in NGOs in Kisumu County do not have skills and abilities required to ensure effectiveness in the implementation of the strategic plans while only $9.52 \%$ of the respondents agreed that their leaders have skills and abilities required to ensure effectiveness in the implementation of the strategic plans. In addition, $31.75 \%$ of the respondents agreed that their leaders creates and nurtures conditions which will enable fast implementation of the strategic plans while $63.49 \%$ of the respondents disagreed with their colleagues.

Furthermore, the findings established that $66.67 \%$ of the leaders in NGOs within Kisumu have not ensured transformational change in the Organization that has enhances implementation of the strategic plans despite the fact that $30.16 \%$ of the respondents supporting that the leaders in NGOs within Kisumu have ensured transformational change in the Organization that has enhances implementation of the strategic plans. On the other hand, nearly half; $41.27 \%$ of the leaders lack clear understanding on the implementation of strategic plans or the ability to successfully implement organizational change while only $53.96 \%$ Finance Officers believed that their leaders have clear understanding on the implementation of strategic plans or the ability to successfully implement organizational change.

Majority of the respondents; $80.96 \%$ affirmed that their perceptions of leadership and decision-making affects their commitments into the implementation of the strategic plans while $17.46 \%$ were on the contrary opinion meaning that their perceptions of leadership and decision-making do not affect their commitments into the implementation of the strategic plans. Another influence of leadership styles on the implementation of the strategic plans in NGOs in Kisumu County was on the classification of leadership styles. Nearly all the respondents; $95.24 \%$ agreed to the fact that whether a leader is classified as a charismatic, a shared, a distributive, a collaborative or an authoritative leader, a new focus may be necessary in order to successfully implement strategic plans.

Moreover, the findings confirmed that majority of the respondents; $70.19 \%$ agreed to the statement that leaders' behavior influences group and organizational behavior 
whereas only $20.63 \%$ of the respondents disagreed. The results further showed that majority of the finance officers $(76.19 \%, 84.13 \%, 85.72 \%$ and $73.01 \%)$ confirmed that Autocratic leadership style, Democratic leadership style, Laissez faire leadership and Transactional and transformational leadership style respectively influences implementation of the strategic plans. However, 20.63\%, $15.87 \%, 12.69 \%$ and $23.81 \%$ of the finance officers disagreed with their colleagues implying that Autocratic leadership style, Democratic leadership style, Laissez faire leadership and Transactional and transformational leadership style respectively do not influences implementation of the strategic plans. The findings concur to findings by Chege, [5] whose regression showed that autocratic leadership had the highest effect of implementation of strategic plans with a coefficient of 0.488 , followed by democratic leadership with a coefficient of 0.384 and laissez faire with a coefficient 0.269 . However, the findings are in contrast to Koech and Namusunge [7] result of the study showed that laissez faire leadership is not significantly correlated to organizational performance.

Furthermore, this objective of the study was tested by developing, the null hypothesis "There is no statistically significant relationship between leadership styles and the implementation of the strategic plans." was tested. To do this a correlation analysis was conducted. The set scores on the leadership styles were used as the independent variable while scores from implementation of the strategic plans was used as the explanatory variable (dependant variable). The results of the correlation are presented in table 4 .

Table 4. Pearson correlation.

\begin{tabular}{llll}
\hline & & Implementation of the strategic plans & Leadership styles \\
\hline Implementation of the strategic plans & Pearson Correlation & 1 & $.854^{* *}$ \\
& Sig. (2-tailed) & \\
& $\mathrm{N}$ & 63 \\
Leadership styles & Pearson Correlation & .000 \\
& Sig. (2-tailed) & $.854^{* *}$ \\
& $\mathrm{~N}$ & 600 \\
\hline
\end{tabular}

The Pearson Product-Moment correlation coefficient ( $\mathrm{r}$ $=.854$ ) computed indicated that there was high positive correlation between leadership styles and the implementation of the strategic plans. The analysis revealed highly significant $(\mathrm{p}<0.05)$ positive relationship between leadership styles and the implementation of the strategic plans, with high levels of leadership styles associated with the fact that that majority of the leaders $(90.48 \%)$ in NGOs in Kisumu County do not have skills and abilities required to ensure effectiveness in the implementation of the strategic plans. In addition, the findings established that $66.67 \%$ of the leaders in NGOs within Kisumu have not ensured transformational change in the Organization that has enhances implementation of the strategic plans despite the fact that $30.16 \%$ of the respondents supporting that the leaders in NGOs within Kisumu have ensured transformational change in the Organization that has enhances implementation of the strategic plans.

Qualitative data from interview was analysed thematically. On the relationship between the leadership and the implementation of strategic plan, a number of respondents were of the view that leadership greatly affects the implementation of strategic plans. This statement concurs to qualitative findings where one of the Human Resource Managers affirmed that, I think one of the challenges affecting our NGOs is due to the lack of adequate knowledge and skills that would rather help in implementation of strategic plans' (Manager 4).

Manager 1 said that, 'I believed that as a leader I should create conducive environment that can raise other leaders which I think I have been in the forefront of doing that and this has improved our implementation techniques as far as strategic plans is concerned'. The findings are in contrast to the sentiments echoed by Kanter, Stein, \& Jick, (2012) who found that leaders have skills, abilities required for effectiveness in change implementation. Leaders in complex organizations are now responsible for creating and nurturing conditions which will enable fast, innovative adaptations to change. However, qualitative findings are concurrent to the findings by Kanter, Stein, \& Jick, (2012).

One of the challenges that we face as leaders is that, 'Majority of our employees have negative attitude when it comes to the strategic plan implantation activities and this has derailed implementation', said by manager 4 . The results concurred to the study by Loveren, [8] whose results indicated that employees' perceptions of leadership, decision-making, and relationships are strongly related to their perceived job satisfaction, trust, commitment, and control mutuality and consequently their perception of the development operation's effectiveness.

In addition, one of the manager quoted that, 'I think our leaders posses different leadership styles where you find that some are charismatic, democratic and even some are dictators and this influence implementation of strategic plan activities', manager 8. Similarly, Ballantyne, [4] established that whether a leader is classified as a charismatic, a shared, a distributive, a collaborative or an authoritative leader, a new focus may be necessary in order to be successful in the new global environment.

Manager 7 also added that, 'Any leadership styles influences strategic plan implementation and therefore it is upon the individual leaders to acquire and practice leadership styles that will enhance implementation of the strategic plans,'

Moreover, manager 10 stated that, I think that most of the leaders in NGOs have not allowed for transformational 
change and this has seriously affected implementation of the strategic plans'. The results are in contrast to Kanter, Stein, \&Jick, [6] who found that in today's business world, organizations that support and implement continuous and transformational change remain competitive.

Furthermore, one manager said that, Leaders are the role models within various NGOs and that their behaviors will in one way or the other affects implementation of the strategic planning activities,' manager 3. The findings are in agreement to the study by Reilly, Caldwel and Self, [13] who established that leaders' behavior influences group and organizational behavior.

One of the manager also had the opinion that majority of the leaders have adequate knowledge in strategic plans implementation is only that they do not have time to ensure effective implementation activities (manager 2). The findings are consistent to the sentiments by Kanter, Stein, \& Jick, [6] who also affirmed that leaders continue to lack a clear understanding on the implementation of strategic plans, its antecedents, effective processes or the ability to successfully implement organizational change and how to engage members in change initiatives.

\section{Conclusion}

According to the findings in the first research objective where the study sought to find out influence of leadership styles on the implementation of the strategic plans in NGOs in Kisumu County. Majority of the leaders (90.48\%) in NGOs in Kisumu County do not have skills and abilities required to ensure effectiveness in the implementation of the strategic plans. In addition, $66.67 \%$ of the leaders in NGOs within Kisumu have not ensured transformational change in the Organization. Moreover, more than half of the leaders lack clear understanding on the implementation of strategic plans or the ability to successfully implement organizational change. Finally, leaders' behavior influences group and organizational behavior and that Autocratic leadership style, Democratic leadership style, Laissez faire leadership and Transactional and transformational leadership style respectively influences implementation of the strategic plans

\section{References}

[1] Allison, M. \& Kaye, J. (2011). Strategic Planning for Nonprofit Organizations: A Practical Guide and Workbook.

[2] Aronson, J. (1995). A Pragmatic View of Thematic Analysis. The Qualitative Report, 2(1), 1-3. Retrieved from http://nsuworks.nova.edu/tqr/vol2/iss $1 / 3$

[3] Baez, B. (2002). Confidentiality in qualitative research: reflections on secrets, power and agency. Qualitative research, 2(1), 35-58.

[4] Ballantyne, S. (2010). Leadership decision-making utilizing a strategic focus to enhance global achievement, Journal of Management and Marketing Research, volume 3, number 4, pages 57-58.
[5] Chege, A. N, (2015). Effects of Leadership Styles on Implementation of Organization Strategic Plans in Small and Medium Enterprises in Nairobi. Management and Administrative Sciences Review Volume 4, Issue 3 Pages: 593600 .

[6] Kanter, R. M., Stein, B. A., \&Jick, T. D. (2012). The challenge of organizational change: How companies experience it and leaders guide it. New York: Free Press.

[7] Koech, P., \&Namusunge, G. S. (2012). Effect of leadership styles on organization performance at state corporation in Kenya. International Journal of Business and Commerce, 2(1), 1-8.

[8] Loveren, R. V. (2007). The Effects of Decision-Making and Leadership Styles on Relationships and Perceived Effectiveness in the University Developme.nt Context, Published PhD thesis, University of South Florida

[9] Matthews, M. R. (2014). International Handbook of Research in History, Philosophy and Science Teaching.

[10] Malunga, C. W. (2009). Improving the effectiveness of strategic planning in local NGOs in Malawi (Doctoral dissertation).

[11] Mertler, C. A., \& Reinhart, R. V. (2016). Advanced and multivariate statistical methods: Practical application and interpretation. Routledge.

[12] Mohamed A. (2013). Challenges of Strategy Implementation faced by International NGOS in Somaliland.

[13] Reilly, A. C., Caldwel, D. F. and Self, W. (2010). How leadership matters: The effects of leaders' alignment on strategy implementation. The Leadership Quarterly 21 (2) 104-113.

[14] Richter, A. and Schmidst, L. S. (2009). How does strategy process influence strategy content? Antecedents of consistency between resource allocation decisions and corporate strategy, Business Review Vol. 57, No. 6 pp. $332-$ 350 .

[15] Schaap, J. (2009). Toward Strategy Implementation Success: An Empirical Study of the Role of Senior-Level Leaders in the Nevada Gaming Industry, 3(4), pages 123-135.

[16] Sullivan, B. K., Martin, A. A., Stewart, M. M., \& Fouquette, M. J. (July 01, 2015). Murray John Littlejohn and Patricia Gordon (Patsy) Littlejohn. Copeia, 103, 2, 467-475.

[17] Suresh, K., \& Chandrashekara, S. (2012). Sample size estimation and power analysis for clinical research studies. Journal of human reproductive sciences, 5(1), 7.

[18] Wallen, N. E., \& Fraenkel, J. R. (2001). Educational research: A guide to the process. Psychology Press.

[19] Weiss, K. and Anderson, J. (2009) Aligning Technology and Business Strategy: Issues \& Frameworks, A Field Study of 15 Companies. Proceedings of the 37th Hawaii International Conference on System Sciences - 2009.

[20] Zambalde, R. and Tonelli, D. (2008) Using the bsc for strategic planning of it (information technology) in brazilian organizations. Journal of Information System Technology and Management vol.11 no.2 240-245. 